\title{
Analysis of Various Smile Parameters Using Digital Photography: An Observational Study
}

\author{
Sushma Ramaswamy ${ }^{1}$, Nikita Rohilla², Tanuja T Sathe ${ }^{3}$
}

\begin{abstract}
Aim and objective: To assess the various smile parameters like smile arc, gingival visibility, dental and facial midlines, gingival zenith, the relation between the upper incisors and the lower lip using digital photography.

Materials and methods: Using a convenient sampling technique a sample size of 120 (60 males and 60 females) was drawn. Both close-up and facial photographs were captured using DSLR [Single-lens reflex digital camera (NIKON)], Lens mount NIKON F mount (with AF contact). Smile arc, gingival visibility, dental and facial midlines, gingival zenith, the relation between the upper incisors and the lower lip were the parameters that were assessed in this study.

Results: The mean age of the male participants was 21.97 and the mean age of female participants was 22.20 . About $81.7 \%$ of the total study population had convex smile arc, $53.3 \%$ of participants had type II gingival visibility for a forced smile, whereas $52.5 \%$ had type $I I$ for a natural smile. About $64.2 \%$ of the subjects had right side deviation of the dental midline, in $21.7 \%$ of the subjects the dental midline coincided with the facial midline. In $81.7 \%$ of the participants, the gingival zenith followed the ideal pattern. In $78.3 \%$, the smile arc slightly touched the upper anteriors. Conclusion: Within the limitations of the present study, it can be concluded that the various smile parameters like smile arc, gingival visibility, dental and facial midline and gingival zenith assessed can be used to rehabilitate the smile of dentate patients, partially dentate, and/or can help rehabilitate an edentulous mouth.

Clinical significance: Dental photography offers the dental professional an array of the possibility of visual reconstruction of the various stages of treatment. With digital photography as an aid, the dentists can design and correct the smile for the utmost satisfaction of the patients.

Keywords: Dental midline, Facial midline, Gingival visibility, Gingival zenith, Smile arc.

World Journal of Dentistry (2021): 10.5005/jp-journals-10015-1856
\end{abstract}

\section{INTRODUCTION}

Poets, painters, writers through the centuries have described a smile as an asset to humans and have emphasized that nothing can be more attractive in a personality than having a beautiful smile. The smile parameters can be based on proportions and parameters like the divine proportion or the golden ratio. ${ }^{1}$ Cosmetic dentistry is a multidisciplinary approach to esthetically rehabilitate a patients' smile. An informed, structured, and disciplined approach is required to assess, diagnose, and restore esthetic problems. The esthetic elements can be drawn into a pleasing arrangement to create a beautiful smile. ${ }^{2}$ Knowledge of the smile parameters of a population would certainly help us in rehabilitating the local population, be it replacing a single tooth or an entire mouth. Many have classified smile one among them is by Ackerman et al. who classified smile into a social smile/posed smile and the enjoyment smile/unposed smile/Duchenne smile depending on the voluntary and involuntary action of orofacial muscles. ${ }^{1}$

Prosthodontics is a branch where lies a delicate amalgamation of scientific principles and creative, artistic capability. With the increasing demands of the patient for an esthetic smile, a thorough and rigorous knowledge about esthetic principles is a must for prosthodontists. Through prosthodontics, one can design various types of smiles depending on facial types.

Generally, a normal photograph and casts are used for evaluating smile parameters. But the normal static photographs can be very vague, cannot provide proper evaluation of smile parameters in depth. And evaluating smile parameters through casts is also not feasible as it does not have an amalgamation of hard and soft tissue. Like our mere existence in the universe is
${ }^{1}$ Department of Prosthodontics and Crown and Bridge, Krishna Institute of Medical Sciences, Karad, Maharashtra, India

${ }^{2}$ Department of Prosthodontics and Crown and Bridge, SDM College, Karnataka, India

${ }^{3}$ Department of Orthodontics, Krishna Institute of Medical Sciences, Karad, Maharashtra, India

Corresponding Author: Sushma Ramaswamy, Department of Prosthodontics and Crown and Bridge, Krishna Institute of Medical Sciences, Karad, Maharashtra, India, Phone: 8767609781, e-mail: doc. sushma.r@gmail.com

How to cite this article: Ramaswamy S, Rohilla N, Sathe TT. Analysis of Various Smile Parameters Using Digital Photography: An Observational Study. World J Dent 2021;12(5):392-398.

Source of support: Nil

Conflict of interest: None

based on quantum physics, the digital field is no exception. Digital gadgets like computers, lasers, camera lenses, etc., all of these work on this basic principle. The cameras used earlier have come a long way with improvements in lens, pixels, etc. Thus, at present, the digital world has so much to offer from which we can benefit to rehabilitate our patients. As smile rehabilitators, our ultimate aim should be to make use of our clinical knowledge and expertise, as well as the digital or the technical support to give our patients the best that they deserve. Dental photography offers the dental professional an array of the possibility of visual reconstruction of the various stages of treatment. ${ }^{3}$ Therefore, digital photographs

(0) Jaypee Brothers Medical Publishers. 2021 Open Access This article is distributed under the terms of the Creative Commons Attribution 4.0 International License (https://creativecommons.org/licenses/by-nc/4.0/), which permits unrestricted use, distribution, and non-commercial reproduction in any medium, provided you give appropriate credit to the original author(s) and the source, provide a link to the Creative Commons license, and indicate if changes were made. The Creative Commons Public Domain Dedication waiver (http://creativecommons.org/publicdomain/zero/1.0/) applies to the data made available in this article, unless otherwise stated. 
have come into the picture, where it provides better efficacy and is nowadays easily available in the market. The disadvantage lies as it is not cost-effective. The present study was undertaken to know the smile parameters of a sample population using the photographs captured in a digital single-lens reflex (DSLR) camera with the intention that the results would help us in prosthodontic rehabilitation of the local population.

\section{Materials and Methods}

Using a convenient sampling technique, a sample size of 120 (60 males and 60 females) was drawn who were selected among the patients visiting the Department of Prosthodontics of the School of Dentistry, Krishna Institute of Medical Sciences Deemed University, Karad, Maharashtra. All patients were informed about the study procedure in their mother tongue and made aware of the experimental design. The study subjects were approached, explained about the study, and their consent was taken.

Inclusion criteria for this study include patients within the range of 18-25 years with a healthy periodontium, complete permanent dentition excluding 3rd molars, class I molar relation with no anterior crowding. Exclusion criteria include patients with any prosthodontic and/or restorative work on teeth visible in a smile, undergone/undergoing orthodontic treatment or maxillofacial surgeries, presence of any periodontal disease, presence of any craniofacial anomalies or other pathologies.

Ethical clearance was obtained from the University's Ethical Committee (KIMSDU/IEC/04/2016). The photographs of the participants were captured using DSLR [Single-lens reflex digital camera (NIKON D3500)] with AF-P 18 to $55 \mathrm{~mm}$ VR lens, lens mount NIKON F mount (with AF contact). Both close-up and facial photographs were captured. The close-ups were taken both during natural and forced smiles. Standardization of the images was done as per Liébart et al. criteria by positioning the head in the Frankfort horizontal plane and capturing the picture from a distance of 30 $\mathrm{cm}$ to include the lateral commissures of the mouth, the teeth, gingiva, and the philtrum of the upper lip. ${ }^{4}$ All the pictures were photographed and evaluated by a single investigator to maintain standardization total of 240 photographs of 120 patients were taken wherein a natural smile photograph and a forced smile photograph (i.e., 2 photographs of each patient) were taken of all participants in this study.
The five parameters considered in the present study are:

- Smile arc

To mark the smile arc, a curve was drawn touching the incisal edges of the upper anterior teeth on the photograph when the subject was instructed to smile naturally. The smile arc was evaluated as positive or negative depending on whether the arc was convex (Fig. 1A) or concave (Fig. 1B) and straight (Fig. 1C)

- Gingival visibility

The amount of gingiva visible on a natural smile and forced smile were recorded. Further, the gingival visibility was divided as type I (Fig. 2A), type II (Fig. 2B), type III (Fig. 2C), type IV (Fig. 2D) according to Liebert et al. classification. ${ }^{4}$

- Facial and dental midline

All the photographs were evaluated for a correlation between the facial and the dental midline. This was done using Adobe Photoshop CS3 version 10.0.5 A line was drawn to mark the facial midline through the nasion, tip of the nose, philtrum, and pogonion and compared with the dental midline which is drawn between the two central incisors. The facial midline was evaluated as ideal (Fig. 3) or canted. The dental midline was evaluated as ideal (Fig. 4A), shift to the right (Fig. 4B), or shift to the left (Fig. 4C).

- Gingival zenith pattern

Horizontal lines on the gingival zenith of central, lateral incisors, and canines were marked as shown in Figure 5 to know the gingival zenith patterns.

- Relationship between the smile arc and lower lip

The relationship between smile arc and lower lip curvature was drawn depending on whether there was a gap between the incisal edges of the upper incisors and the lower lip (Fig. 6A) or there was light contact of maxillary incisal edges with lower lip (Fig. 6B).

In the present study, the sample size considered according to the convenient sampling technique was 120 (N). Statistical analysis was performed using SPSS software, version 23. The mean and standard deviation (SD) were calculated for age. Frequency and percentage were calculated for gender and other parameters. Chi-square test and Fisher's exact test were used to check the association between gender and various parameters. Comparison between two groups (male and female) for various parameters was done by non-parametric Mann-Whitney " $U$ " test. The $p$ value of 0.05 was considered to be statistically significant.
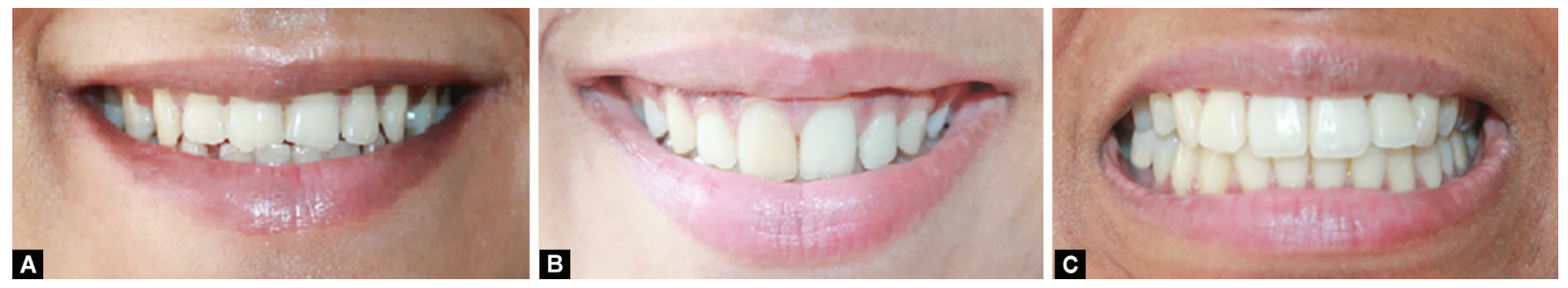

Figs 1A to C: Smile arc: (A) Convex smile arc; (B) Concave smile arc; (C) Straight smile arc
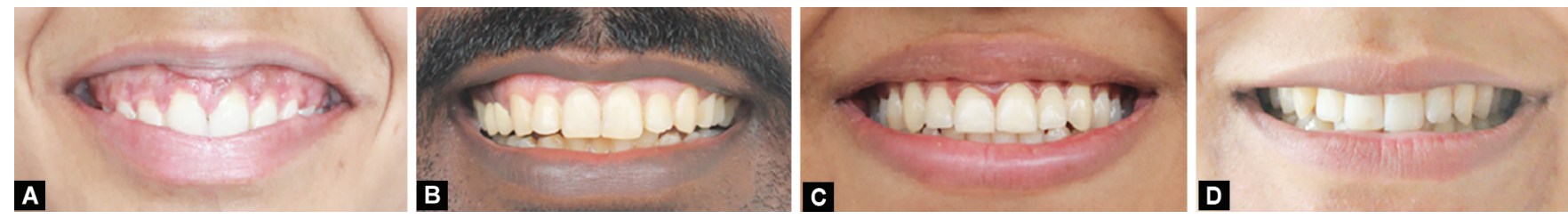

Figs 2A to D: Types of gingival visibility: (A) Type I gingival visibility; (B) Type II gingival visibility; (C) Type III gingival visibility; (D) Type IV gingival visibility 


\section{Results}

Table 1 shows the age distribution in the study population, respectively. Among males $N(60), 85.0 \%(N=51)$ of them had convex smile arc. Among females $N(60), 78.3 \%(N=47)$ of them had convex smile arc. Within the genders when the smile arc was compared using the Mann-Whitney " $U$ " test, $81.7 \%(N=98)$ of the study population had convex smile arc (Table 2 ) which was statistically insignificant $(p=0.429)$.

Gingival visibility according to Liebert et al. assessed for normal and forced smiles in both genders. ${ }^{4}$ Results obtained for gingival visibility for both forced and normal smiles in both genders had a higher percentage of type II type of gingival visibility. When the gingival visibility was compared in both the genders for forced smile $53.3 \%(N=64)$ had type II type of gingival visibility (Table 3 ) which was statistically insignificant $(p=0.979)$. And for normal smile $52.5 \%(N=63)$ had type II (Table 3 ) which was statistically insignificant ( $p=0.802$ ). From the results, it can be conveniently drawn that the majority of the population had type II type of gingival visibility. However, it is interesting to note that there was not even a single study subject who had a type I gingival visibility score for both normal and forced smiles.

In 39 of the males, i.e., $65.0 \%$ and 38 , i.e., $63.3 \%$ of the female study subjects, the dental midline was found to deviate to the right. When the Mann-Whitney " $U$ " test was applied to compare the midline deviation within the genders in 77 , i.e., $64.2 \%$ of the study subjects the dental midline was found to deviate to the right. The results obtained were statistically insignificant $(p=0.624)$. With the data it can be concluded that the majority of the study population the midline is deviated to the right side, followed by the dental midline coinciding with the facial midline, and in the least number of study subject's midline was found to deviate to the left side (Table 4).

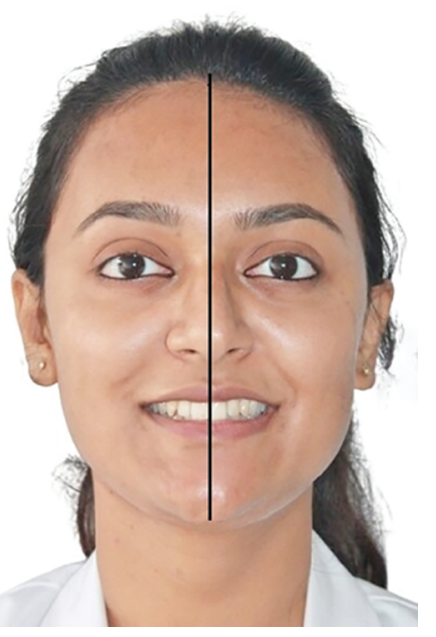

Fig. 3: Ideal facial midline
Among the males $N=50,83.3 \%$ followed the ideal zenith pattern. Among the females $N=48,80.0 \%$ of them followed the zenith pattern. When the zenith pattern was compared within the genders in the study population using Mann-Whitney " $U$ " test about $N=98,81.7 \%$ followed the zenith pattern (Table 5) which was statistically insignificant $(p=0.814)$. With these data, it can be said that about $80 \%$ of the study population followed the ideal zenith pattern. When the relationship between the incisal edges of upper anteriors and lower lip was evaluated in the male study population, $N=43,71.1 \%$ and $N=51,85.0 \%$ of females had incisal edges of upper anteriors touching the lower lip which directly relates to the positive smile arc. When this relation was studied between the genders using Fisher's exact test in $N=94,78.3 \%$ of the study population the lower lip was in contact with upper anteriors (Table 5) which was statistically insignificant $(p=0.120$ ).

\section{Discussion}

A pleasing smile can be created by arranging various esthetic components in harmony. ${ }^{1}$ The dental discrepancies are evaluated differently by laypeople, general dentists, and restorative dentists. ${ }^{6}$

Multiple photographic views (e.g., facial, sagittal) facilitate the smile analysis. ${ }^{7}$ A dentist should always look forward to an ideal goal that would lead him toward proper diagnosis and treatment planning for smile rejuvenation. ${ }^{8}$ Clinical photography has become an important part of standard dental practice. ${ }^{9}$

The area of presentation of a smile lies in-between the upper and lower lips. Our teeth and the gingival mesh are an integral part of the smile. The lip thickness, inter-commissural width, inter-labial gap, smile index (width/height), and gingival architecture are the soft tissue definitive for the area of presentation of a smile. ${ }^{10}$ The various parameters of the smile that were assessed in this study are discussed below.

\section{Smile Arc}

Smile arc varies with individuals. When the smile line is convex or concave, it is referred to as a smile curve. The facets of a smile are

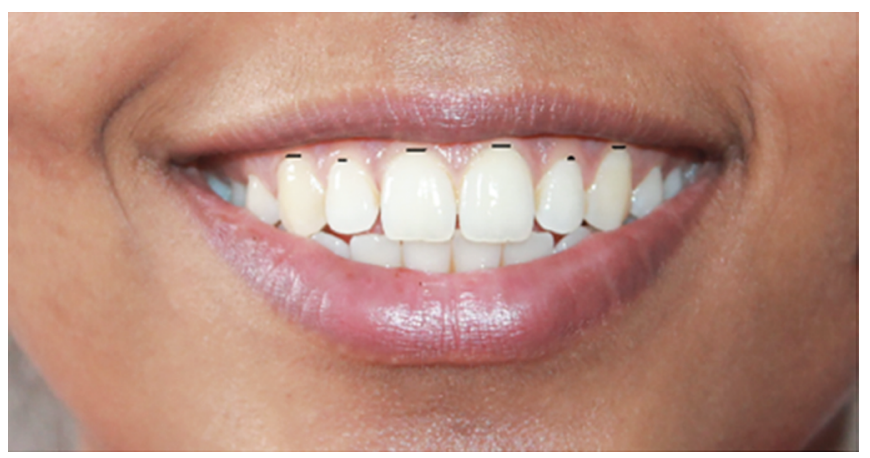

Fig. 5: Gingival zenith
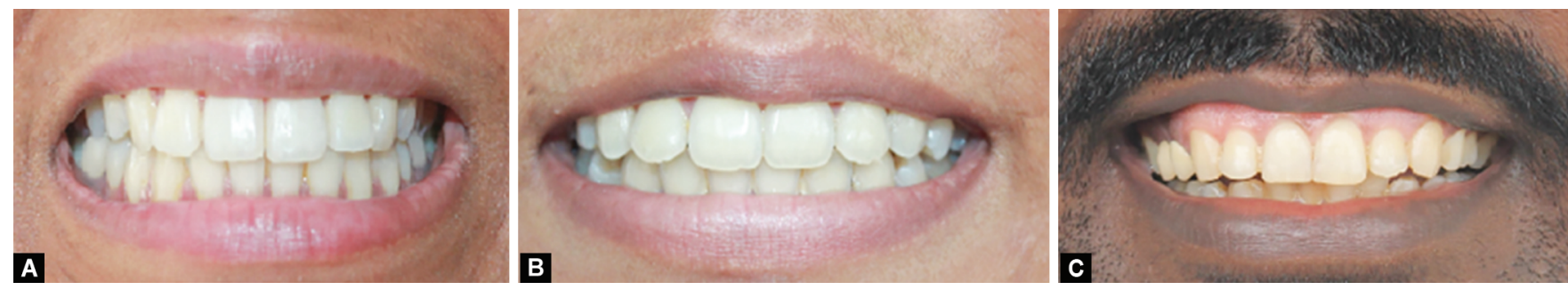

Figs 4A to C: Dental midline: (A) Ideal; (B) Shift to the right; (C) Shift to the left 

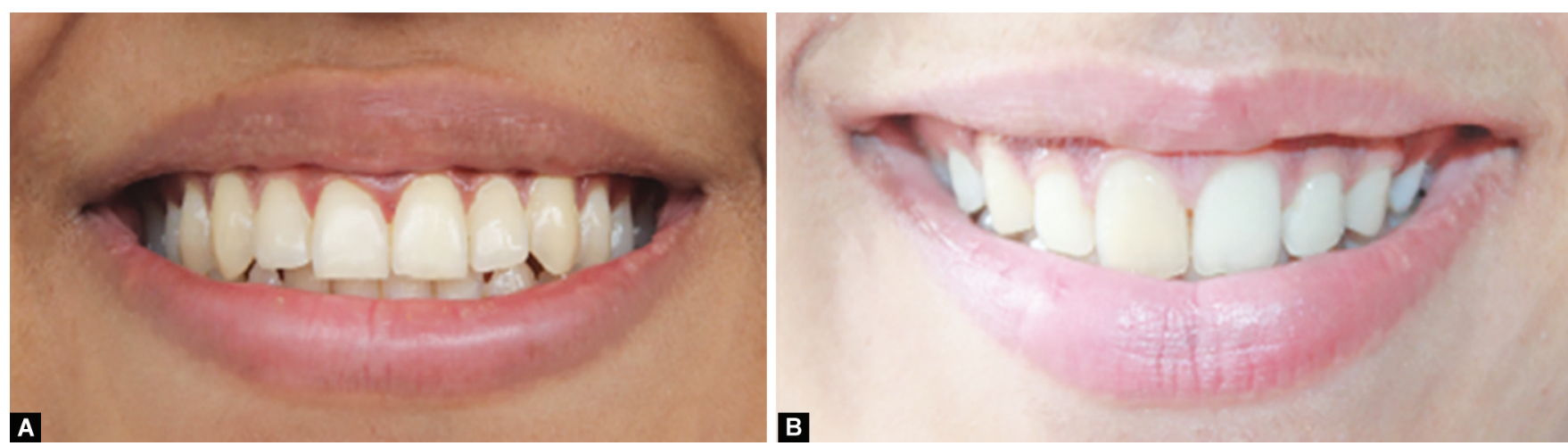

Figs 6A and B: Relationship between smile arc and lower lip: (A) A gap between the incisal edges of the upper incisors and the lower lip; (B) Light contact of maxillary incisal edges with the lower lip

Table 1: Age distribution among the study population

\begin{tabular}{lcclllll}
\hline & Sex & $N$ & Minimum & Maximum & Mean & Std. deviation & $p$ value \\
\hline Male & Age & 60 & 19 & 24 & 21.97 & 1.104 & 0.344 \\
Female & Age & 60 & 20 & 24 & 22.20 & 0.898 & 1.009 \\
Combined & Age & 120 & 19 & 24 & 22.08 & \\
\hline
\end{tabular}

*Statistically insignificant

Table 2: Comparison among male and female for smile line distribution among study by Mann-Whitney " $U$ " test

\begin{tabular}{|c|c|c|c|c|c|c|c|}
\hline & & & \multicolumn{3}{|c|}{ Smile line } & \multirow[b]{2}{*}{ Total } & \multirow[b]{2}{*}{$p$ value } \\
\hline & & & Convex & Concave & Straight & & \\
\hline \multirow[t]{4}{*}{ Sex } & Male & Count & 51 & 2 & 7 & 60 & $0.429^{*}$ \\
\hline & & $\%$ within sex & 85.0 & 3.3 & 11.7 & 100.0 & \\
\hline & Female & Count & 47 & 7 & 6 & 60 & \\
\hline & & $\%$ within sex & 78.3 & 11.7 & 10.0 & 100.0 & \\
\hline \multirow[t]{2}{*}{ Total } & Count & 98 & 9 & 13 & 120 & & \\
\hline & $\%$ within sex & 81.7 & 7.5 & 10.8 & 100.0 & & \\
\hline
\end{tabular}

*Statistically insignificant

highlighted by the convex smile and therefore it is been called a positive smile line. And the converse is true for a concave smile where it represents a strident, unpleasant, and distracting feature of a smile hence is called a negative smile line. A straight smile line could pose a positive or negative effect depending on its harmony to the lip curvature and the presence or, absence of a buccal corridor. ${ }^{11,12}$ The survey revealed that the most frequent smile line in females and males both was convex, i.e., 78.3 and $85.0 \%$, respectively, with the average of $81.7 \%$ followed by straight, i.e., $10.8 \%$ and concave, i.e., $7.5 \%$. The is in direct agreement with studies of Tjan and Miller, ${ }^{13}$ Zachrisson. ${ }^{13,14}$ All these studies are in direct agreement with each other and with the present study stating a higher percentage of a convex smile.

\section{Gingival Visibility}

Gingival exposure can be differentiated during smile or speech, which is mainly because of the structures pertaining to the dental and muscular zone like upper and lower lip muscle mobility and strength, clinical crown length, lip vertical length, and skeletal relationship, mainly vertical maxillary length. ${ }^{14,15}$ In this study, the gingival visibility was recorded during the forced and natural smile. The results of our study revealed that the most common type was a high line (type II) for both males and females with an average of $52.5 \%$ during normal smiles and an average of $53.3 \%$ during forced smiles in both males and females study subjects. However, this is not in agreement with the study done by Binam Sapokta et al. where the least percentage of participants had a very high type of natural smile $1.4 \%$ and a very high type of forced smile $15.9 \%{ }^{16}$

In a study done in the Nepali population, maximum participants had a low type of natural smile, i.e., 59.1\% and average type of forced smile, i.e., $40.0 \%{ }^{6}$ This is similar to a previous finding of Dayakar et al. in Indians with a higher percentage favoring low type of natural smile $67 \% .{ }^{16}$ The findings of the present study were not similar to the results of the study done in Europe by Liebart et al., where most common was an average type for both normal $44.79 \%$ and forced smile $45.49 \%{ }^{4}$

\section{Facial and Dental Midlines}

Esthetically, the midline is the most important crucial spot in a smile. ${ }^{17}$ Boucher recommends that "the long axis of central incisors should be parallel to the long axis of the face and the midline of the dental arch should be located near the middle of the face". ${ }^{18}$

To achieve the dental midline synchronizing with the facial midline would be tough as it is controlled by the patient factor. Moreover, if there are any discrepancies in the midline facial structures it may cumbersome the analysis of dental midline position. ${ }^{19}$

Avinash et al. studied the relationship between the midline of the face and mouth with that of the facial anatomic landmarks 


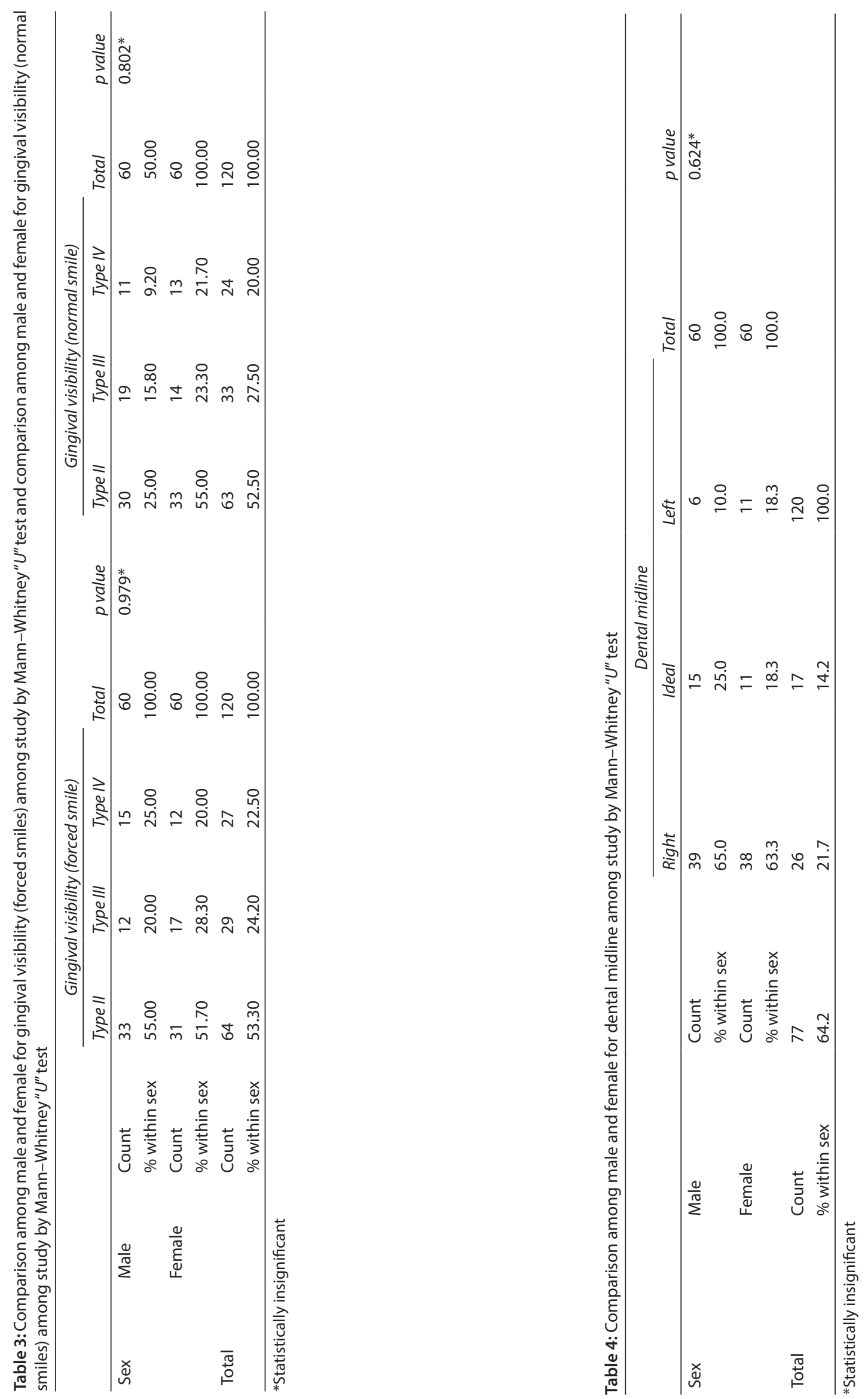




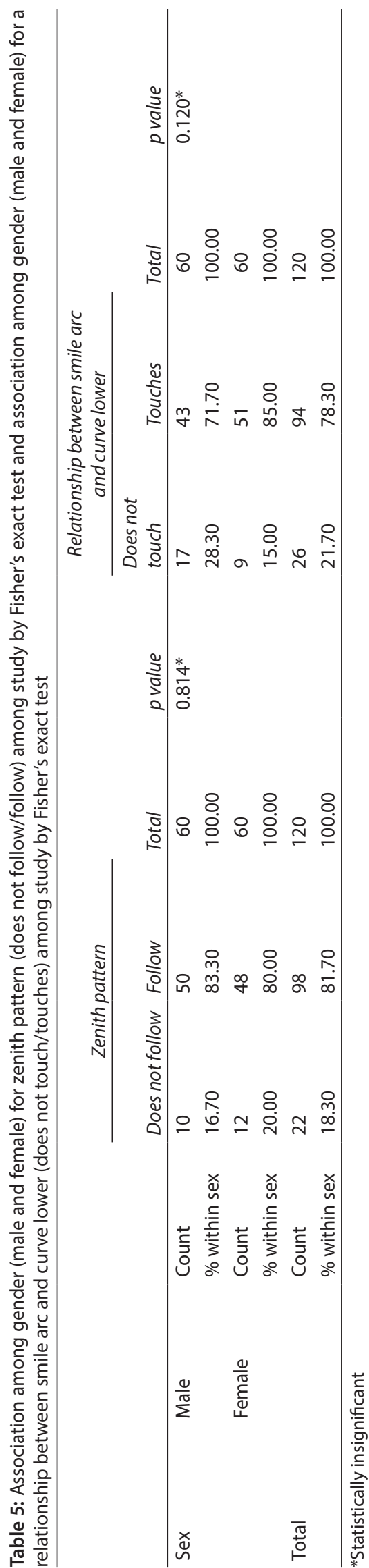

and stated that "hierarchy of anatomic landmarks closest to the midline of the face are (i) midline of the commissure, (ii) dental midline (iii) tip midline discrepancy more than $2 \mathrm{~mm}$ is esthetically unacceptable". ${ }^{20}$

The results of the present study were in direct agreement with the study carried by Dayakar et al. ${ }^{21}$ wherein $40 \%$ of male subjects showed the deviation of midline toward the right, $8 \%$ coincided with the midline, and $20 \%$ showed deviation toward the left $0.72 \%$ of female subjects showed the deviation of midline toward the right, $8 \%$ showed deviation toward the left. Another study done by Sharma showed that in 290 , i.e., $72.5 \%$ of the maxillary midline was coinciding with facial midline, whereas in 110 , i.e., $27.5 \%$ of subjects the maxillary midline was otherwise in a total of 400 study subjects. ${ }^{22}$

\section{Gingival Zenith Pattern}

The gingival zenith (GZ) is the most apical aspect of the free gingival margin. Gingival zenith line (GZL) is defined as "the line joining the tangents of the gingival zeniths of the central incisor and canine". Consider an individual maxillary anterior tooth, and distal to the vertical bisected midline (VBM) axis lies the gingival zenith position (GZP). Considering the gingival zenith is of utmost importance while following the various procedures like crown lengthening, implant, restorative, and orthodontic therapy, gingival line, and zenith. ${ }^{23,24}$

It is mostly seen that the zenith of the central incisor is at the distal third, that of the lateral incisors is in the middle, and the one with the canines ranges from anterior third through to the distal third. By changing the line angle position of the long axis of the tooth, the position of the zenith will help create the desired axial inclination. ${ }^{24}$

Mattos et al. with a sample of 50 healthy individuals marked gingival zenith as the highest scalloped gingiva and a perpendicular bisector to gingival zenith level as vertical bisected midline. ${ }^{25}$ Kay has also stated that the gingival zenith of incisors teeth lies distal to their long axis. ${ }^{26}$ Goodlin also observed that gingival zenith lies at distal third in case of central incisor, at the VBN for lateral incisor and in canine, it lies between the anterior third to the distal third of the crown. ${ }^{27}$

This study revealed that 83.3 and $80 \%$ of the male and female participants, respectively, followed the zenith pattern with an average of $81.7 \%$. The results were consistent with the study conducted by Humagain et al. ${ }^{23}$

\section{Relation between the Smile Arc and Lower Lip}

While evaluating a smile on its esthetic basis, a dentist should always keep in mind that the relation of contact between the lower lip and the incisal edges of maxillary teeth is also important. ${ }^{13,28}$

If a line is drawn along the incisal edges of the maxillary anterior teeth, it should follow the curvature of the superior border of the lower lip during smiling which is recognized as a smile line. If the centrals appear shorter than the canines along the incisal plane, then it is referred to as a reverse smile line which will lead to an unesthetic appearance when the patient smiles. So here it is important that in complete dentures fabrication reverse smile line should not be entertained. ${ }^{29,30}$

Another factor contributing to the esthetic effects of a smile is the contact between the lower lip and incisal edges or the labial surface of the upper anterior teeth. If there is a contact present between the incisal edges of upper teeth and the vermillion border of the lower lip, then it is considered an attractive smile. A negative 
smile is the one where there is the absence of parallelism between the smile line and lower lip together with no contact of incisal edges with the lower lip. ${ }^{10}$ Due to wear by abrasion, erosion or attrition, periodontitis, altered patterns of eruption, or poor-quality dentistry, there is a lack of coincidence between the incisal table and the mandibular lip.

The ideal relationship is recognized when the incisal edges of the upper incisors are parallel to the upper border of the lower lip and a few millimeters apart from it or softly touching the lower lip, provided dental and labial structures are symmetrica. ${ }^{31}$ This relationship depends on muscle contraction of the lower lip and mouth opening. According to Tjan and Miller, incisal edge of maxillary anterior teeth touching the lower lip is esthetic. ${ }^{12}$ In our study $43,71.7 \%$ male and $51,85.0 \%$ female incisal edges or the labial surface of upper anterior teeth touches the lower lip which is consistent with another study by Dayakar et al. and Meshramkar et al. ${ }^{21,28}$

\section{Limitations of the Study}

The study was performed on smiles captured by clinical photography which was a static record. Adobe Photoshop is used in this study; however, advanced softwares are available which can be considered for further studies.

\section{Conclusion}

Within the limitations of the present study, it can be concluded that the various smile parameters assessed can be used to rehabilitate the smile of dentate patients, partially dentate, and/or can help rehabilitate an edentulous mouth. The present study was done to evaluate some aspects of the dento-labial-gingival complex using photographs. Knowledge of smile design, coupled with new and innovative dental technologies, allows dentists to diagnose, plan, create, and deliver esthetically pleasing new smiles.

\section{References}

1. Manjula WS, Sukumar MR, Kishore Kumar S, et al. Smile: a review. J Pharm Bioall Sci 2015;7(Suppl 1):S271-S275. DOI: 10.4103/09757406.155951.

2. Bhuvaneswaran M. Principles of smile design. J Conserv Dent 2010;13(4):225. DOI: 10.4103/0972-0707.73387.

3. Manjunath SG, Ragavendra RT, Setty SK, et al. Photography in clinical dentistry-a review. Int J Dent Clin 2011;3(2):40-43.

4. Liébart MF, Fouque-Deruelle $C$, Santini A, et al. Line and periodontium visibility. Period Practice Today 2004;1(1):17-25.

5. Soares GP, Valentino GA, Lima DA, et al. Esthetic analysis of smile. Braz J Oral Sci 2007;6:1313-1319.

6. Kokich VO, AsumanKiyak H, Shapiro PA. Comparing the perception of dentists and lay people to altered dental esthetics. J EsthetRestor Dent 1999;11(6):311-324. DOI: 10.1111/j.1708-8240.1999.tb00414.x.

7. McLaren EA, Culp L. Smile analysis. J CosmetDent 2013;29(1):94-108.

8. Davis NC. Smile design. Dent Clin N Am 2007;51(2):299-318. DOI: 10.1016/j.cden.2006.12.006.

9. McLaren EA, Terry DA. Photography in dentistry. J Calif Dent Assoc 2001;29(10):735-742.
10. Ackerman MB, Ackerman JL. Smile analysis and design in the digital era. J Clin Orthod 2002;36(4):221-236.

11. Kaur G, Patnaik VV, Kaushal S. The anatomy of a smile. J Med Colle Chandigarh 2011;1(1):20-23.

12. Câmara CA. Esthetics in orthodontics: six horizontal smile lines. Dent Press J Orthod 2010;15(1):118-131. DOI: 10.1590/S217694512010000100014.

13. Tjan AH, Miller GD. Some esthetic factors in a smile. J Prosthet Dent 1984;51(1):24-28. DOI: 10.1016/s0022-3913(84)80097-9.

14. Zachrisson BU. Esthetic factors involved in anterior tooth display and the smile: vertical dimension. J Clin Orthod 1998;32:432-445.

15. Ritter DE, Gandini Jr LG, Pinto Ados S, et al. Analysis of the smile photograph. World J Orthod 2006;7(3):279-285.

16. Sapkota B, Srivastava S, Koju S, et al. Evaluation of smile line in natural and forced smile position: an institution-based study. Orthod J Nepal 2017;7(1):27-32. DOI: 10.3126/ojn.v7i1.18898.

17. Kiran PS, Chander KS, Annapurna PD, et al. Examination and correlation of facial midline and skeletal midline to dental midline by photographic and radiographic anaylsis respectively. Indian J Dent Sci 2015;7(1):11-15.

18. Hickey JC, Zarb GA, Bolender CL. Prosthodontic treatment for edentulous patients. St. Louis: CV Mosby Company; 1975. pp. 365-367.

19. Beyer JW, Lindauer SJ. Evaluation of dental midline position. Semin Orthod 1998;4(3):146-152. DOI: 10.1016/s1073-8746(98)80016-9.

20. Bidra AS, Uribe F, Taylor TD, et al. The relationship of facial anatomic landmarks with midlines of the face and mouth. J Prosthet Dent 2009;102(2):94-103. DOI: 10.1016/S0022-3913(09)60117-7.

21. Dayakar MM, Shipilova A, Rekha M. Evaluation of smile esthetics by photographic assessment of the dento-labio-gingival complex. J Dent Alli Sci 2015;4(2):65. DOI: 10.4103/2277-4696.171515.

22. Sharma V, Khandelwal M, Punia V. Correlation of facial to dental midline and maxillary to mandibular midline in karnataka population. Ann Essen Dentis 2011;3(1):20-24.

23. Humagain $M$, Rokaya $D$, Srii $R$, et al. Gender based comparison of gingival zenith esthetics. Kathmandu Univ Med J 2016;54(2):148-152.

24. Charruel S, Perez C, Foti B, et al. Gingival contour assessment: clinical parameters useful for esthetic diagnosis and treatment. J Clin Period 2008;79(5):795-801. DOI: 10.1902/jop.2008.070488.

25. Mattos CM, Santana RB. A quantitative evaluation of the spatial displacement of the gingival zenith in the maxillary anterior dentition. J Periodontol 2008;79(10):1880-1885. DOI: 10.1902/ jop.2008.080053.

26. Kay HB. Esthetic considerations in the definitive periodontal prosthetic management of the maxillary anterior segment. Int J Periodont Rest 1982;2(3):44-59.

27. Goodlin R. Cosmetic dentistry-gingival aesthetics--a critical factor in smile design. Oral Health 2003;93(4):10-28.

28. Meshramkar RD, Agarwal R, Pillai LK, et al. Study to evaluate some of the esthetics factors determining attractive smile. Int J Prosthodont Restor Dent 2016;6(2):31-36. DOI: 10.5005/jp-journals-10019-1151.

29. Rajtilak G, Deepa S, RajasekarV, et al. Anterior teeth and smile design: a prospective view. Int J Period Restorat Dent 2012;2(3):117-127.

30. Lapatki BG, Baustert D, Schulte-Mönting J, et al. Lip-to-incisor relationship and postorthodontic long-term stability of cover-bite treatment. Angle Orthod 2006;76(6):942-949. DOI: 10.2319/090205309.

31. Sarver DM, Ackerman MB. Dynamic smile visualization and quantification: part 1. Evolution of the concept and dynamic records for smile capture. Am J Orthod Dentofacial Orthop 2003;124(1):4-12. DOI: 10.1016/s0889-5406(03)00306-8. 